\title{
Pressure Testing of a Minimum Gauge PRSEUS Panel
}

\author{
Andrew E. Lovejoy ${ }^{1}$ and Marshall Rouse ${ }^{2}$ \\ NASA Langley Research Center, Hampton, VA 23681 \\ and \\ Kim A. Linton ${ }^{3}$ and Victor P. $\mathrm{Li}^{4}$ \\ The Boeing Company, Seal Beach, CA 90740
}

\begin{abstract}
Advanced aircraft configurations that have been developed to increase fuel efficiency require advanced, novel structural concepts capable of handling the unique load conditions that arise. One such concept is the Pultruded Rod Stitched Efficient Unitized Structure (PRSEUS) developed by the Boeing Company. The PRSEUS concept is being investigated by NASA's Environmentally Responsible Aviation (ERA) Program for use in a hybrid-wing body (HWB) aircraft. This paper summarizes the analysis and test of a PRSEUS panel subjected to internal pressure, the first such pressure test for this structural concept. The pressure panel used minimum gauge skin, with stringer and frame configurations consistent with previous PRSEUS tests. Analysis indicated that for the minimum gauge skin panel, the stringer locations exhibit fairly linear response, but the skin bays between the stringers exhibit nonlinear response. Excellent agreement was seen between nonlinear analysis and test results in the critical portion at the center of the panel. The pristine panel was capable of withstanding the required 18.4 psi pressure load condition without exhibiting any damage. The impacted panel was capable of withstanding a pressure load in excess of 28 psi before initial failure occurred at the center stringer, and the panel was capable of sustaining increased pressure load after the initial failure. This successful PRSEUS panel pressure panel test was a critical step in the building block approach for enabling the use of this advanced structural concept on future aircraft, such as the HWB.
\end{abstract}

\section{Introduction}

Tn an effort to increase the fuel efficiency of aircraft, numerous configuration concepts have been developed. One such concept is the hybrid-wing body (HWB) shown in Fig. 1, which is the current focus of NASA's Environmentally Responsible Aviation (ERA) Program. The HWB design combines features of a flying wing with features of conventional transport aircraft. This configuration has the advantage of simultaneously increasing both fuel efficiency and payload. ${ }^{1,2}$ Early in the formulation of the HWB concept, it was realized that conventional structural configurations of the time limited the potential design space for lightweight primary structure. Therefore, the conventional pressurized cabin structure was abandoned with the expectation that future structural concepts would be developed that were capable of sustaining the encountered HWB loads. ${ }^{2}$ As a result, initial HWB research focused on the aerodynamic, stability and control issues (flying characteristics), which included wind tunnel tests at NASA Langley Research Center (LaRC). While later studies have continued to address HWB flying characteristics, including noise and propulsion issues, recent years have seen an increased focus on the structural performance of the HWB. ${ }^{3-8}$ This increased focus is due to the fact that structures technology still does not yet satisfy the expected structural capabilities required to facilitate HWB aircraft.

Conventional round fuselage sections react cabin pressure by hoop tension. However, the structural configuration of the HWB subjects the majority of the structural panels to bi-axial, in-plane loads in addition to the internal cabin pressure. Therefore, the design and sizing of these nearly flat pressurized panels (shown by the shaded

\footnotetext{
${ }^{1}$ Aerospace Engineer, Structural Mechanics \& Concepts Branch, MS 190, Senior Member AIAA, Member ASME.

${ }^{2}$ Senior Aerospace Engineer, Structures Testing Branch, MS190, Senior Member AIAA.

${ }^{3}$ Senior Design Engineer, Advanced Structures, Boeing Research \& Technology.

${ }^{4}$ Senior Structural Analysis Engineer, Boeing Research \& Technology, Associate Fellow AIAA.
} 
region in Fig. 2) requires more thorough examination and analysis than conventional transport aircraft components that have traditional and less complex load paths. Several sizing and optimization studies have been conducted on HWB-like structures. ${ }^{3,4,6,7}$ Of particular importance is the response of the non-circular HWB structure subjected to internal pressure, where double bending curvature (center and edges of the panel bending in opposite directions) is experienced by the pressurized panel that results in large local stresses that drive the panel design. This phenomenon is discussed in Refs. 3 and 7, and emphasizes the potential inefficiency of a uniform panel design unless the structural concept is highly efficient. One structural concept that shows great promise for application to a HWB center section is the Pultruded Rod Stitched Efficient Unitized Structure (PRSEUS) ${ }^{9}$ developed by the Boeing Company. This paper summarizes analysis and testing of a PRSEUS panel subjected to internal pressure that was tested at NASA LaRC.

\section{PRSEUS Pressure Panel and Building Block Approach}

PRSEUS is an integral structural concept that evolved out of stitching technology development from a NASABoeing program in the 1990's ${ }^{5,10-13}$ whereby skins, frames, stringers and tear straps are all stitched together, then infused and cured in an out-of-autoclave process. ${ }^{9}$ An expanded view of a PRSEUS stiffener intersection is shown in Fig. 3. The key to the PRSEUS concept is the pre-cured, pultruded rod that is contained within the stringer wrap plies and which passes through the frames, providing an uninterrupted load path. At the same time, the full depth frame stiffener is also continuous, except for the key-hole through which the stringer passes, providing an uninterrupted load path in the direction perpendicular to the stringer. These efficient structural stiffening members provide the majority of the panel stiffness, permitting the use of minimum skin thickness for many applications.

The tested pressure panel shown in Fig. 4 is a flat panel comprising two frames spaced 20.0 inches apart and 15 stringers spaced 6.0 inches apart, with outer dimensions of 108 x 48 inches. This panel was fabricated from warpknit fiber architecture stacks of dry AS4 carbon fiber, pultruded carbon fiber rods and Rohacell foam. The prekitted stacks had a stacking sequence of $\left[45 /-45 / 0_{2} / 90 / 0_{2} /-45 / 45\right]_{\mathrm{T}}$, which results in a stack thickness of approximately 0.052 inches. The pultruded rods were Toray unidirectional T800 fiber with a 3900-2B resin, and the frame stiffeners were filled with Rohacell foam. Stringer and frame cross-sections are shown in Fig. 5. Nominal stringer and frame heights, measured from the outer mold line, are 1.49 and 6.0 inches, respectively. The skin, frames, and stringers were stitched into a dry perform that was infused with HexFlow VRM 34 resin using Boeing's Controlled Atmospheric Pressure Resin Infusion (CAPRI) process. ${ }^{9}{ }^{14}$ The pressure panel tested utilizes the minimum skin gauge of one stack, or 0.052 inches. Complete details of the pressure panel design and fabrication can be found in Ref. 14.

Under the HWB structural development program, a building block approach has been used to design, analyze, build and test structural components. The PRSEUS pressure panel, which is the focus of this paper, is the first PRSEUS structure to be loaded by internal pressure. It fits into the sub-component testing portion of the Technology Readiness Level (TRL) 4 development effort. The pressure panel was designed, analyzed and fabricated by Boeing, ${ }^{14}$ and was tested at NASA LaRC.

\section{Test Specification}

\section{A. Test Set-up}

The PRSEUS pressure panel was bolted to the pressure vessel as shown in Fig. 6. The opening on the top of the fixture is $100 \times 40$ inches, and represents the effective test section dimensions for the pressure panel. External metallic doublers were bonded to the pressure panel around its perimeter, as shown in Fig. 6. Also shown in Fig. 6 are the external stiffeners that are integral to the doublers along the long edges of the panel, and are coincident with the stringer locations. These external stiffeners provided bending continuity and tie the stringers to the pressure vessel. The panel was bolted to the pressure vessel through the doubler region with double rows of fasteners, as shown in Fig. 6. A speckle pattern, also shown in Fig. 6, consisting of white and black paint was applied to the outer surface of the panel prior to testing. The speckle pattern was used with a digital image correlation system, ${ }^{15}$ VIC$3 \mathrm{D}^{16}$ (referred to here-in as VIC), that was used to monitor displacements and strains. Strain gages were used to monitor strains on the inner and outer surfaces, center stringer, one end stringer, and frames. The gage patterns are shown in Figs. 7 and 8, along with the key used for gage identification. Gages are numbered, followed by several identifiers that indicate information about the gage placement and orientation. Gages designated with an " $\mathrm{A}$ " refer to outer surface gages, and with a "B" refer to inner surface gages. The subscript letter following the surface designation refers to the location of the gage, followed by the orientation angles $0^{\circ}$ and $90^{\circ}$ that refer to the gage being oriented along the frame and stringer directions, respectively. For example, gage $1 \mathrm{~B}_{\mathrm{R}}, 90^{\circ}$ is gage number 1 , 
located on the inner surface on the stringer rod, oriented along the length of the stringer. Fewer gages were used on the outer surface as the primary purpose of the external gages was to augment the VIC data. As an additional supplement to the VIC system, displacement at the center of the skin bay adjacent to the center stringer, without strain gages, was monitored using a laser displacement sensor mounted to the inside of the pressure vessel. A laser displacement sensor was used to avoid potential interference to a conventional LVDT due to wire vibration that may result from the air being introduced during pressurization. Pressure was introduced through a 1-inch union fitting using an air supply that was nominally at 90.0 psi. Over pressurization was prevented by a pressure relief valve set for 30.0 psi.

\section{B. Test Procedure}

Testing of the PRSEUS pressure panel was conducted at the Combined Loads Test Systems (COLTS) ${ }^{17}$ facility located at NASA LaRC. The COLTS facility was used due to its ability to isolate the test setup and contain the energy released in case of a catastrophic failure of the panel or the pressure vessel. The panel was pressurized using the three load levels: 1) pristine panel pressurized to $9.2 \mathrm{psi}$, 2) pristine panel pressurized to $18.4 \mathrm{psi}$, and 3) impacted panel pressurized to 30 psi. Load level 1 represents the normal operating pressurization (1P), with the 18.4 psi pressure of load level 2 representing the over-pressurization requirement (2P) that the panel must sustain without damage. A pressure of $30 \mathrm{psi}$ was chosen for load level 3 because it exceeds both the required $2 \mathrm{P}$ ultimate pressure load and the predicted initial failure load that is presented in Section IV. Increasing pressure load was controlled at a maximum rate of 1.5 psi per minute, with periodic holds to allow pressure stabilization. Data was continuously recorded from load initiation until the designated level of pressure was reached, and back to zero. Depressurization occurred at a maximum rate of 2.5 psi per minute, and the pressure was reset to zero before continuing onto the next load level. Real-time strain gage data and VIC data was monitored throughout the process, and data was recorded at a rate of $1 \mathrm{~Hz}$. Prior to the final failure test (load level 3), the panel was impacted with $20 \mathrm{ft}-\mathrm{lbs}$ of energy (maximum internal damage level) using a spring-loaded impact apparatus. Details associated with the impact are discussed in Section V.

\section{Pre-test Analysis}

A finite element model (FEM) was created using MSC/PATRAN ${ }^{18}$ and analyzed using the MSC/NASTRAN ${ }^{19}$ finite element code. The pressure panel FEM, shown in Fig. 9, consists of nearly 140,000 nodes and nearly 140,000 elements and was modeled using shell and beam elements. A much coarser pressure vessel FEM was created that was modeled using shell elements. The panel FEM was connected to the pressure vessel FEM using connector elements at the bolt locations. Linear static analysis was conducted to obtain the pre-test predictions. The displacement pattern for a load of $2 \mathrm{P}$ is shown in Fig. 10. The maximum predicted panel displacement is approximately 0.666 inches near the skin mid-bay on either side of the center stringer. Maximum and minimum skin principal strains are shown in Figs. 11 and 12, respectively. Similarly, the maximum and minimum stringer rod strains are shown in Figs. 13 and 14, respectively. The linear analysis indicates that the critical compressive strains occur in the rods, with the three center stringer rods having similar strain levels. The most critical strains in the skin occur near the corners of the panel test area, and are a result of the boundary condition effects. Pre-test analysis results predicted that the impacted panel would fail at a pressure load of around $27.6 \mathrm{psi}$, and that the failure would be located in the center stringer rod at the panel center.

\section{Test Results and Discussion}

Load level 1 was applied to verify that the pressure control and data acquisition systems were operating as expected. Upon successfully completing load level 1, load level was 2 was applied to evaluate the behavior of the pristine panel subjected to the $2 \mathrm{P}(18.4 \mathrm{psi})$ ultimate pressure condition that is required of pressurized aircraft structure. The panel withstood the pressure and exhibited no damage under load level 2. Out-of-plane displacement contours from the VIC system are shown in Fig. 15a, with a maximum displacement of 0.653 inches near the center of the panel. The pre-test linear analysis predicted a 0.666 inch displacement, which is only $2 \%$ higher than the VIC value, but the contour patterns are significantly different, as shown in Fig. 15b. Therefore, a nonlinear static analysis was conducted. Maximum displacement predicted by the nonlinear analysis was 0.608 inches, which is $7 \%$ lower than the VIC value. However, the VIC test data and nonlinear analysis agree extremely well in displacement contour pattern as shown in Fig. 15c. The test results indicate that the minimum gauge skin exhibited nonlinear behavior under pressure load. However, the displacement at the stringers does not exhibit nonlinear behavior as both the linear and nonlinear analyses predict center stringer maximum displacement of 0.584 inches. A final displacement comparison is made in Fig. 16, where the analysis predictions are compared to the laser displacement transducer 
data. Also shown in the Fig. is the VIC measurement at the same location at 2P. At this particular location, the linear and nonlinear analysis displacement predictions are $19.6 \%$ and $9.0 \%$ greater than the measured laser value, respectively. However, because the VIC displacement value is bracketed by the analysis results, and because the laser measurement does not start on the same slope as the analysis data, it is possible that the laser measurement is not accurate. To further assess the accuracy of the VIC data, strain values obtained from the VIC data were compared to the strains of outer surface gages at the center of the panel. Very good agreement was found for these strain values. Therefore, it was determined that the laser displacement measurement was in error in magnitude. Due to the manner in which the laser data deviates from the analysis data, this error in displacement magnitude may be due to an incorrect conversion factor being used to convert the laser signal to a displacement value. However, the laser measurement is capable of indicating when failure events occur by identifying discontinuities in displacement, so the laser data was used to identify failure load for load level 3.

Strain gage data also shows the trend that the stringer locations exhibit linear behavior, while the skin bays exhibit nonlinear behavior. Load level 2 strain gage plots are shown in Figs. 17 - 21, where test data are represented by the solid lines, linear analysis results are represented by long dashed lines, and nonlinear analysis results are represented by short dashed lines. Recall that the 0-degree direction is aligned with the frames, the 90-degree direction is aligned with the stringers, and the lower numbered gages are located on the inside surface of the panel. Figure 17 clearly shows that the measured strains on the center stringer exhibit linear response. However, Figs. 18 and 20 clearly show that the 0 -degree center skin bay and stringer flange strains adjacent to the center stringer exhibit nonlinear response. Gages numbered 6 and 30 are back-to-back at the center of the skin bay, and gages numbered 4 and 34 are back-to-back near the stringer flange edge. Figs. 18 and 20 show that while the linear analysis predicts the initial slope of the strain response, it quickly deviates from the true response as the pressure increases. On the other hand, Fig. 18 shows excellent agreement and Fig. 20 shows very good agreement between the nonlinear analysis and test. Similar response is seen in Figs. 19 and 21 for the back-to-back 90-degree strain gages at the center of the panel (numbers 5 and 31 on the skin, and numbers 3 and 35 on the flange). Although strains at the edge of the panel adjacent to the center stringer near the panel edge were significantly lower than at the center of the panel, strain gages were also examined and compared to the analyses. While the nonlinear analysis showed much better agreement with the test data than the linear analysis, significant deviation from the test results was observed. This discrepancy is most likely due to the boundary effects and the response of the frames. Boundary effects can result from the presence of the sealant that was used to seal the panel to the pressure vessel, from bolt slippage, etc. that are typical of test configurations where true experimental boundary conditions don't necessarily correspond to analytical boundary conditions. The effects due to frame response are discussed subsequently in relation to load level 3.

Prior to applying load level 3, the panel was impacted with barely visible impact damage (BVID) at an impact energy of $20 \mathrm{ft}-\mathrm{lbs}$. This energy level is meant to represent the ultimate force that a tool drop or other such event would impart on the inside surface of an aircraft, and has been used on previous PRSEUS tests. ${ }^{14}$ A spring-loaded impactor was used with a 1-inch diameter impact tup. The impactor was positioned against the side of the center stringer to inflict an impact at an angle of approximately 40 degrees measured from the plane of the panel. However, during execution, the impact apparatus slipped, and the impactor had a glancing blow to the skin, and then impacted the side of the stringer adjacent to the center stringer. Figure 22 shows the impact locations. Since the angle of impact with the skin was very shallow, it is believed that the impact to the adjacent stringer was very close to the desired $20 \mathrm{ft}-\mathrm{lb}$ energy level. Previous testing has shown that little effect is seen to the response and failure load due to impacts at this energy level to either the top or side of the rod region. ${ }^{14}$ Also, since the strains in the stringers adjacent to the center stringer are almost the same as those in the center stringer, it was concluded that this impact was sufficient so no additional impact was imparted.

The VIC out-of-plane displacement plot from load level 2 (Fig. 15a) shows a slight offset in the displacement field. This offset suggested unsymmetric response of the frames during pressurization, and is a possible cause for the difference between analysis and load level 2 test response for some gages near the edge of the panel. Unsymmetric response of the frames could be due to initial geometric imperfections in the frames or boundary condition effects. Therefore, also prior to applying load level 3, the frames were checked for straightness using a twisted pair of white and black thread as shown in Fig. 23. This straightness check indicated that both frames appeared to be very straight, and therefore it is unlikely that initial imperfection of the frames caused this unexpected frame response. In order to monitor bending of the frames during load level 3, additional strain gages were added to either side of the frame tops at the center of the frame length, and were identified simply by numbers $42-45$. Gages 42 and 43 are back-to-back on the frame top adjacent to the gages at the edge of the panel shown in Figs. 7 and 8, with gage 42 being located on the side of the frame toward the center of the panel. Gages 44 and 45 are back-to-back on the other frame top, with gage 44 being located on the side of the frame toward the center of the panel. 
The pressure panel was tested to $30 \mathrm{psi}$ for load level 3. The VIC system was available only for real-time monitoring during load level 3 due to errors that occurred with the VIC data recording that precluded postprocessing. The laser displacement transducer out-of-plane displacement measurement is shown in Fig. 24. A jump in displacement occurred at a pressure of $28.44 \mathrm{psi}$, and was accompanied by a loud bang from the panel. This loud bang was the first audible sound emitted by the panel throughout the three test sequences. Loading continued up to 30 psi with no additional sounds emanating from the panel. Strain gage data is plotted in Figs. $25-30$ for load level 3 and shows similar jumps in value at the 28.44 psi pressure level. Figs. $25-28$ show the strain data for the same gages as presented for load level 2, with the same response up to 18.4 psi. Strain response continued in an expected manner up to a pressure of 28.44 psi. Specifically, the response for strain gage number 1, shown in Fig. 25 and located on the center stringer, indicates a failure of the stringer. The sudden strain drop in the center stringer gages shown in Fig. 25, coupled with the outer surface strain increases in the skin and flange gages adjacent to the center stringer shown in Figs. 26 - 29, are clear indications that the failure occurred in the center stringer.

Fig. 30 shows the response for frame gages $42-45$. Gages 42 and 43 clearly indicate bending of the frame. The lower strain value on gage 43 indicates that the frame is bending toward the edge of the panel until the center stringer fails, at which time the frame jumps to bending toward the center of the panel. Gages 44 and 45 show that the other frame does not exhibit any bending until after the center stringer fails, as the strain plots are coincident up to failure of the center stringer. After failure of the center stringer, this frame also bends towards the center of the panel. This unsymmetric response of the frames exhibited during the test is contrary to the finite element analysis, which predicts that both frames exhibit symmetric behavior and bend toward the center of the panel throughout the entire pressurization sequence.

Post-test examination of the panel confirms that the load shift was associated with a failure of the center stringer. Figs. 31 and 32 show the two sides of the center stringer, where the locations of the stitching on the stringer web and flange are shown indicated by dashed lines. Failure is evident in the stringer wrap at the rod location, and damage progresses down the stringer web to the flange. The damage was arrested between the lower stringer web stitching and the stringer flange stitching while the panel was loaded beyond the 28.44 psi level. The pressure was increased to the maximum test pressure of $30 \mathrm{psi}$, and the damaged panel was able withstand this increased loading without any indication of further damage. The initial failure at 28.44 psi was $3.0 \%$ above the analytically predicted value of $27.6 \mathrm{psi}$ for the pristine panel. As has been mentioned, previous testing has shown little effect to the load carrying capability of the PRSEUS rod when impacted with the level of energy used, so it is not unexpected that the analysis of the pristine panel accurately predicts the response of the panel with BVID on the stringer.

\section{Conclusion}

The first pressure test of a PRSEUS panel was successfully conducted as a building block towards developing HWB structure for a full-scale aircraft. The test showed that the pristine PRSEUS panel was able to withstand the required $18.4 \mathrm{psi}, 2 \mathrm{P}$ internal pressure loading condition with no evidence of damage. After BVID was inflicted to a primary load-carrying member, the panel was still able to withstand the required $2 \mathrm{P}$ load condition, and supported 28.44 psi prior to initial failure through the center stiffener. Damage was arrested, and the panel was then loaded to 30 psi without additional damage. Initial failure occurred at a load 3\% higher than predicted by analysis, and significantly higher than required for commercial transport aircraft. Excellent agreement between the analysis and test results away from the test panel boundaries, and an accurate prediction of the initial failure load indicates that current analysis techniques are capable of accurately predicting PRSEUS panel response at the macroscopic structural level. This successful test was a critical step forward in enabling the use of this advanced structural concept on future HWB aircraft.

\section{References}

${ }^{1}$ Liebeck, R., "Design of the Blended-Wing-Body Subsonic Transport," Paper AIAA-2002-0002, 40th AIAA Aerospace Sciences Meeting \& Exhibit, Reno, Nevada, January 14-17, 2002.

${ }^{2}$ Liebeck, R., "Design of the Blended Wing Body Subsonic Transport," Journal of Aircraft, Vol. 41, No. 1, January-February, 2004, pp. 10-25.

${ }^{3}$ Lovejoy, A., "Optimization of Blended Wing Body Composite Panels Using Both NASTRAN and Genetic Algorithm," NASA-CR-214515, October 2006.

${ }^{4}$ Mukhopadhyay, V., "Blended-Wing-Body (BWB) Fuselage Structural Design for Weight Reduction," AIAA Paper 20052349, 46th AIAA/ASME/ASCE/AHS/ASC Structures, Structural Dynamics and Materials Conference, Austin, Texas, April 1821, 2005.

${ }^{5}$ Velicki, Alex, and Hansen, Dan, "Novel Blended Wing Body Structural Concepts," NRA-03-LaRC-02 Maturation for Advanced Aerodynamic and Structures Technologies for Subsonic Transport Aircraft: Phase I Final Report, July 13, 2004. 
${ }^{6}$ Mukhopadhyay, V., Sobieszczanski-Sobieski, J., Kosaka, I., Quinn, G., and Charpentier, C., "Analysis Design and Optimization of Non-cylindrical Fuselage for Blended-Wing-Body (BWB) Vehicle," AIAA Paper 2002-5664, 9th AIAA/ISSMO Symposium on Multidisciplinary Analysis and Optimization, Atlanta, Georgia, September 4-6, 2002.

${ }^{7}$ Vitali, R., Park, O., Haftka, R. T., Sankar, B. V., and Rose, C. A., "Structural Optimization of a Hat-Stiffened Panel Using Response Surfaces," Journal of Aircraft, Vol. 39, No. 1, January-February, 2002, pp. 158-166.

${ }^{8}$ Engels, H., Becker, W., and Morris, A., "Implementation of a Multi-level Optimisation Methodology Within the E-design of a Blended Wing Body," Aerospace Science and Technology, Volume 8, 2004, pp. 145-153.

${ }^{9}$ Velicki, A., "Damage Arresting Composites for Shaped Vehicles, Phase I Final Report," NASA CR-2009-215932, September 2009

${ }^{10}$ Air Vehicle Technology Integration Program (AVTIP), Delivery Order 0059: Multi-role Bomber Structural Analysis, AFRL-VA-WP-TR-2006-3067, K. Hoffman, MAY 2006, Final Report for 14 December 2004 - 08 May 2006, AFRL-VA-WPTR-2006-3067.

${ }^{11}$ Karal, M., “AST Composite Wing Study - Executive Summary,” NASA/CR-2001-210650, Prepared for NASA, Langley Research Center under Contract NAS1-20546, March 2001.

${ }^{12}$ Velicki, A. and Thrash, P. J., "Advanced Structural Concept Development Using Stitched Composites," 49th AIAA/ASME/ASCE/SHS/ASC Structures, Structural Dynamics, and Materials Conference, 7-10 April 2008, Schaumburg, IL, AIAA Paper 2008-2329.

${ }^{13}$ Jegley, D., "Influence of Impact Damage on Carbon-Epoxy Stiffener Crippling," American Society for Composites meeting, Sept 2010, Dayton, OH.

${ }^{14}$ Velicki, A., Yovanof, N., Baraja, J., Linton, K., Li, V., Hawley, A., Thrash, P., DeCoux, S. and Pickell, R., "Damage Arresting Composites for Shaped Vehicles - Phase II Final Report,” NASA CR-2011-216880, January 2011.

${ }^{15}$ McGowan, D. M., Ambur, D. R, and McNeil, S. R., "Full-field Structural Response of Composite Structures: Analysis and Experiment," $44^{\text {th }}$ AIAA/ASME/ASCE/AHS Structures, Dynamics and Material Conference, AIAA 2003-1623, Norfolk, VA, April 2003.

${ }^{16}$ Correlated Solutions, Inc., 120 Kaminer Way Parkway Suite A, Columbia, SC 29210 (http://www.correlatedsolutions.com).

${ }^{17}$ Ambur, D. A., Rouse, M., Starnes, J. H., and Shuart, M. J., "Facilities for Combined Loads Testing of Aircraft Structures to Satisfy Structural Technology Development Requirements," $5^{\text {th }}$ NASA/DoD Advanced Composites Technology Conference, Seattle, WA, August 22-25, 1994.

${ }^{18}$ MSC.PATRAN Reference Manual, MSC.Software Corporation, Santa Ana, CA, 2003.

${ }^{19}$ MSC.NASTRAN 2004 Reference Manual, MSC.Software Corporation, Santa Ana, CA, 2003.
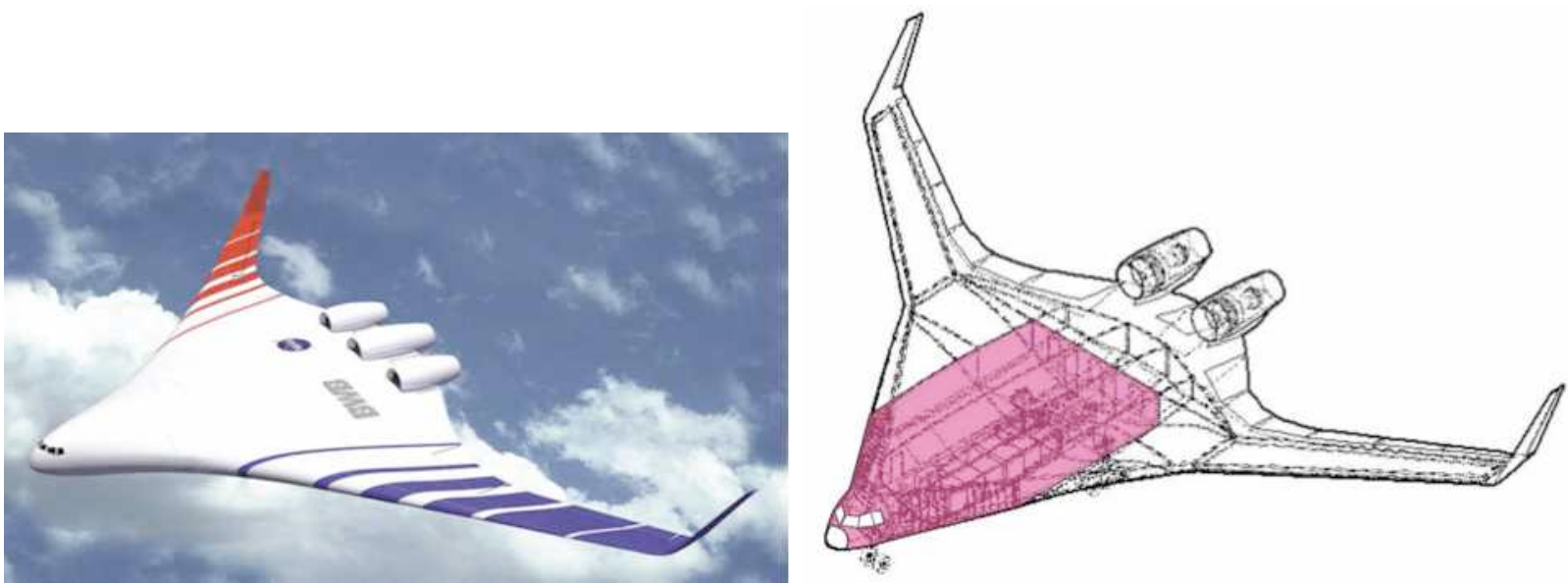

Fig. 1. HWB aircraft concept.

Fig. 2. Typical pressurized portion of a HWB aircraft concept. 


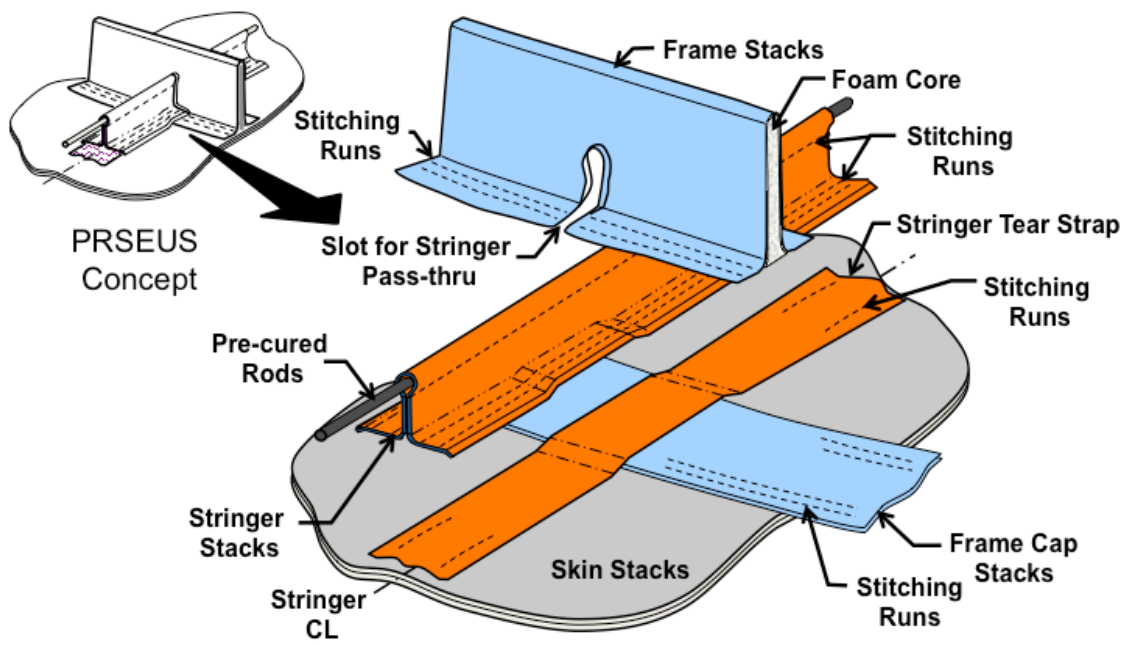

Fig. 3. PRSEUS stiffener intersection expanded view.

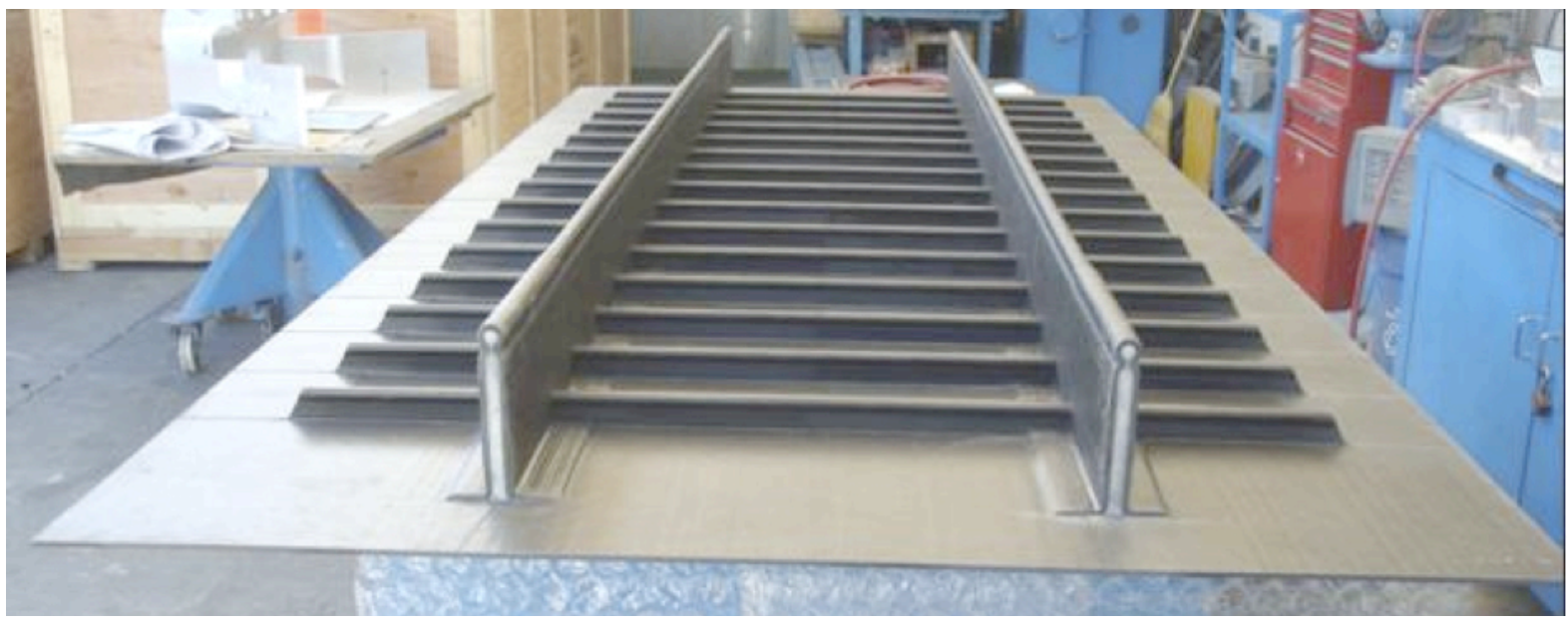

Fig. 4. PRSEUS pressure panel.

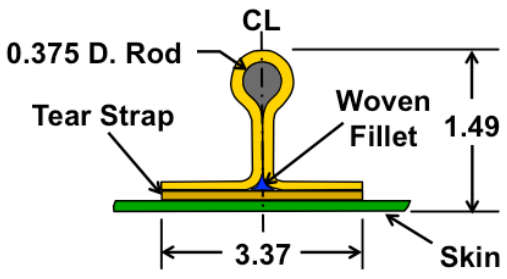

a) Stringer

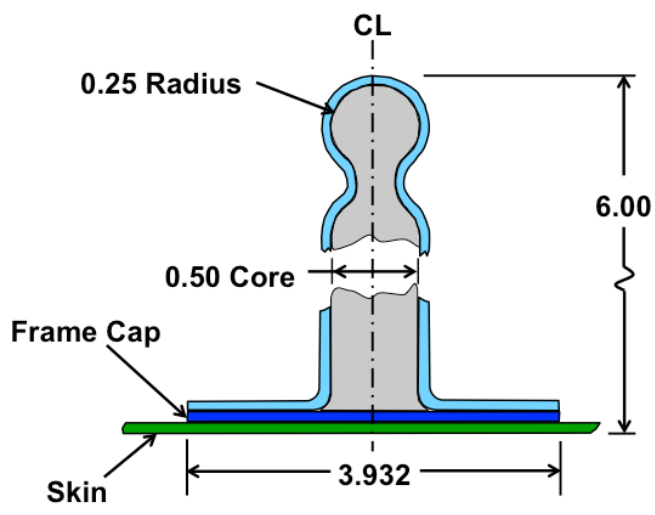

b) Frame

Fig. 5. PRSEUS panel stringer and frame cross-sections. Dimensions are in inches. 

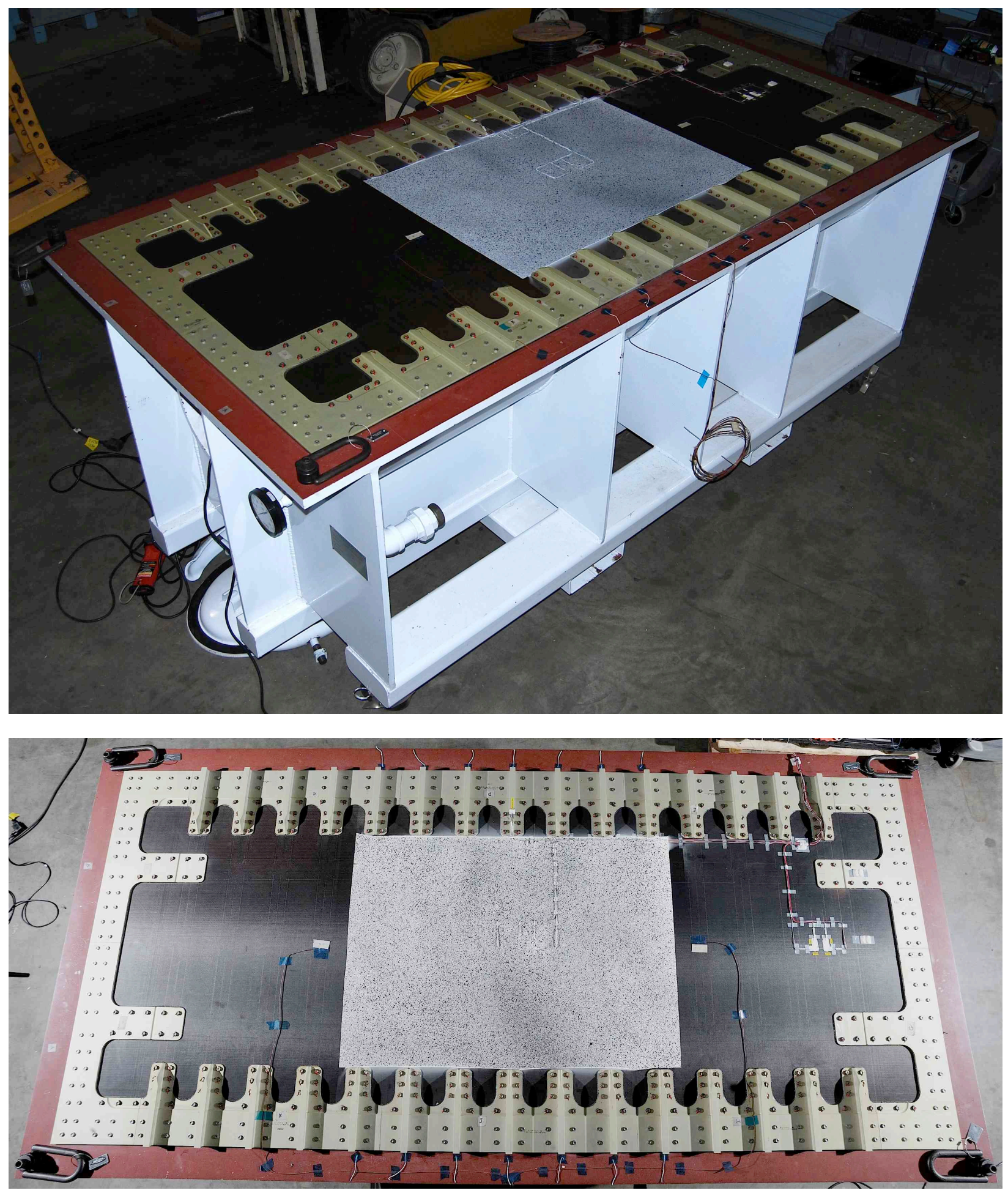

Fig. 6. Test assembly - pressure panel attached to pressure vessel with double rows of fasteners. Doublers are the yellow structure around the perimeter, with integral stiffeners seen along long edges. The VIC speckle pattern is the white region in the center and measures approximately 29 by 40 inches. 


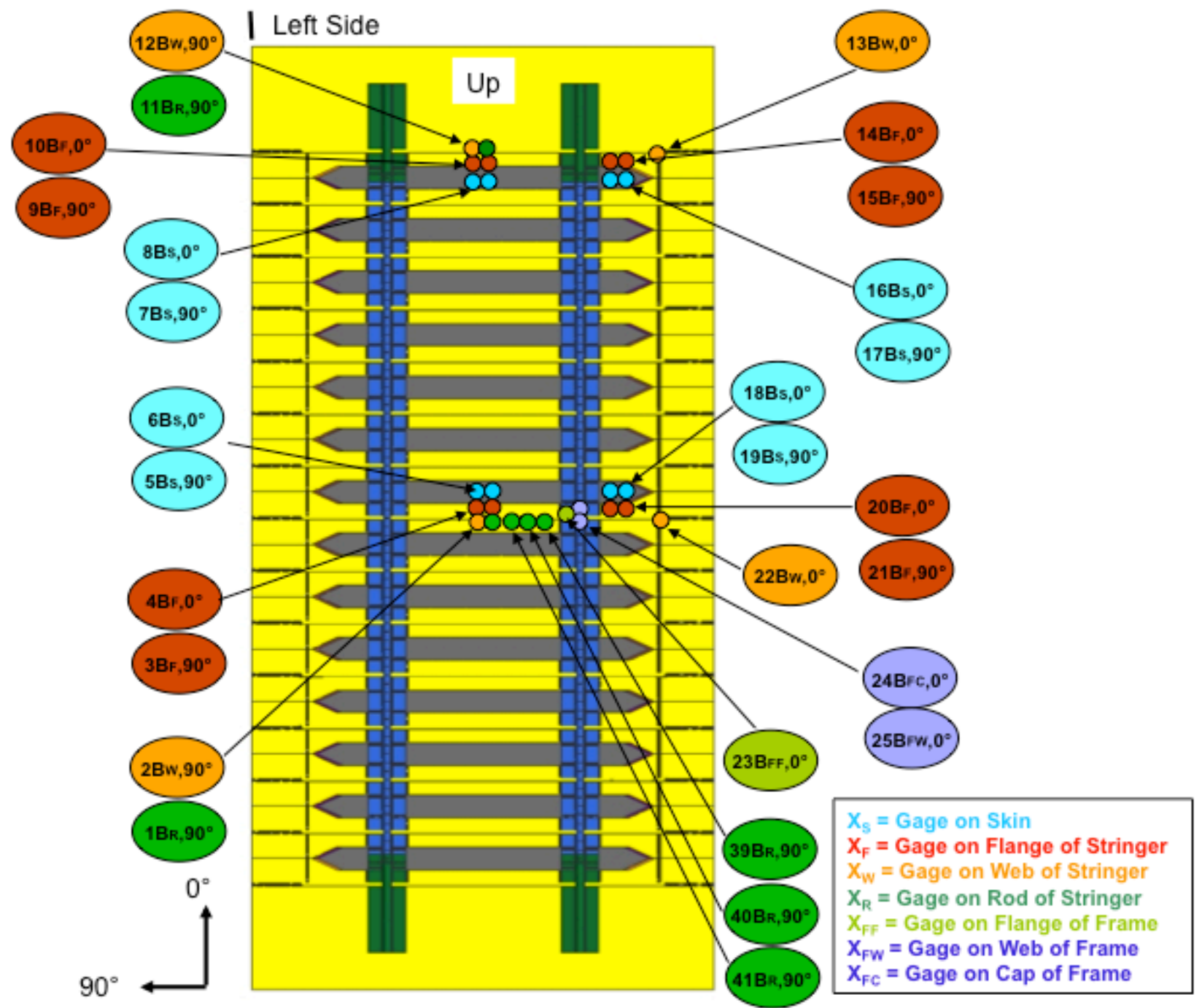

Fig. 7. Inner surface strain gage designations and locations. 


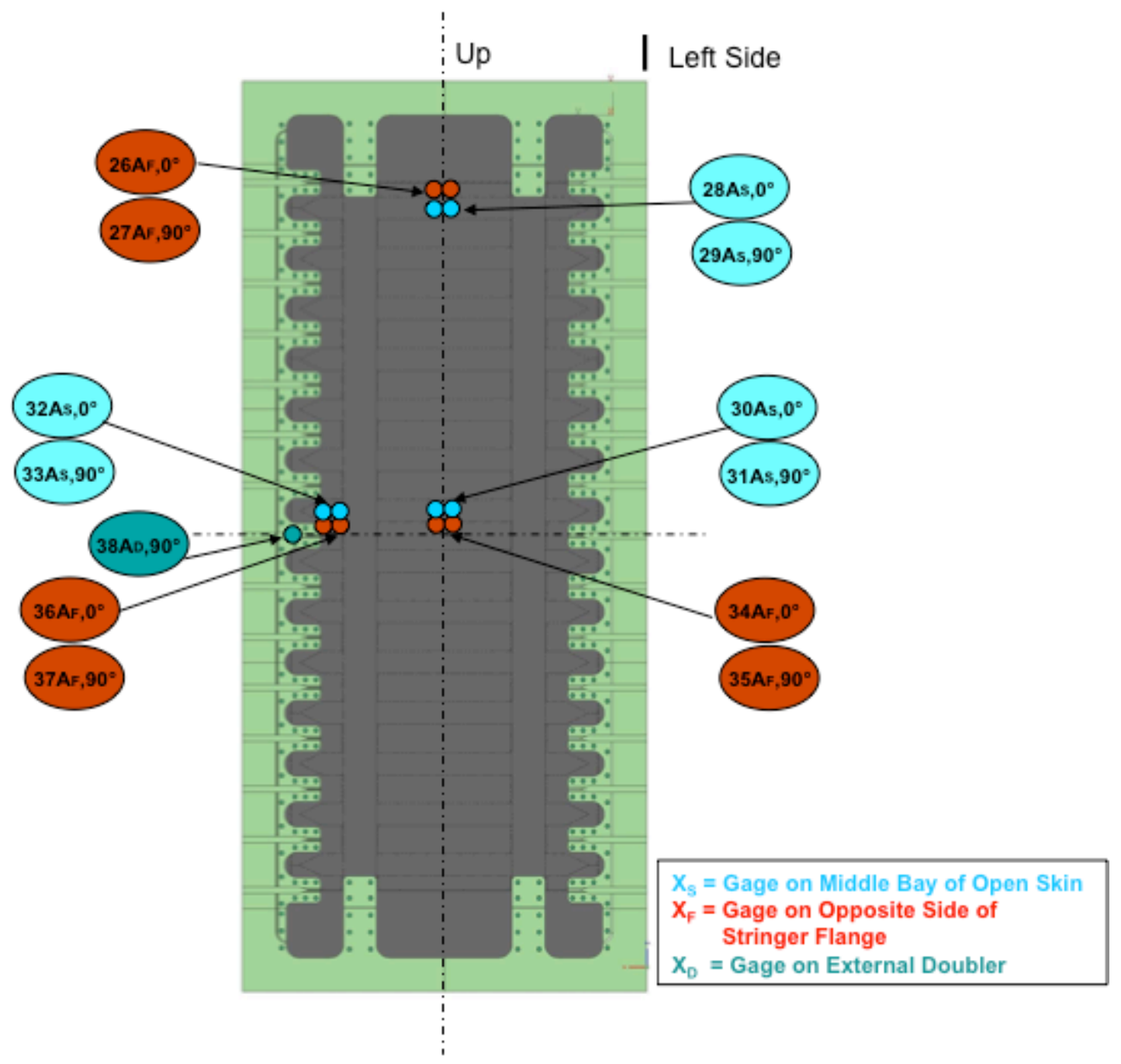

Fig. 8. Outer surface strain gage designations and locations. 


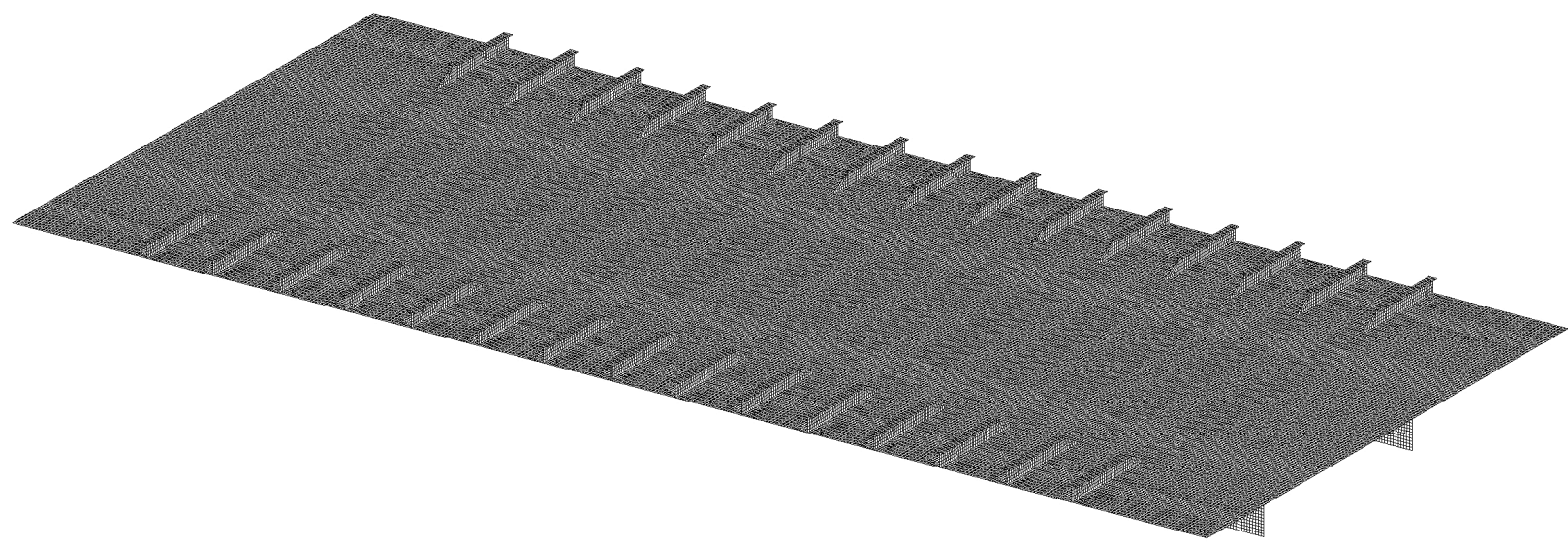

Fig. 9. Pressure panel FEM with bonded doublers included.

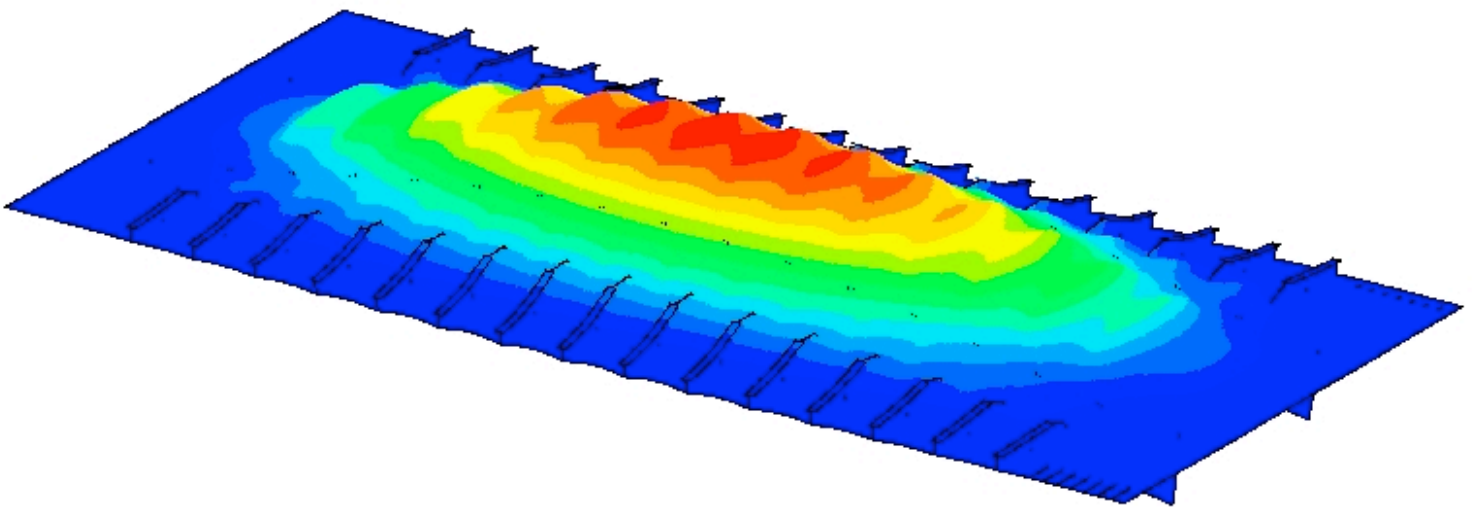

Fig. 10. Pressure panel displacement pattern at $2 P$ from linear analysis.
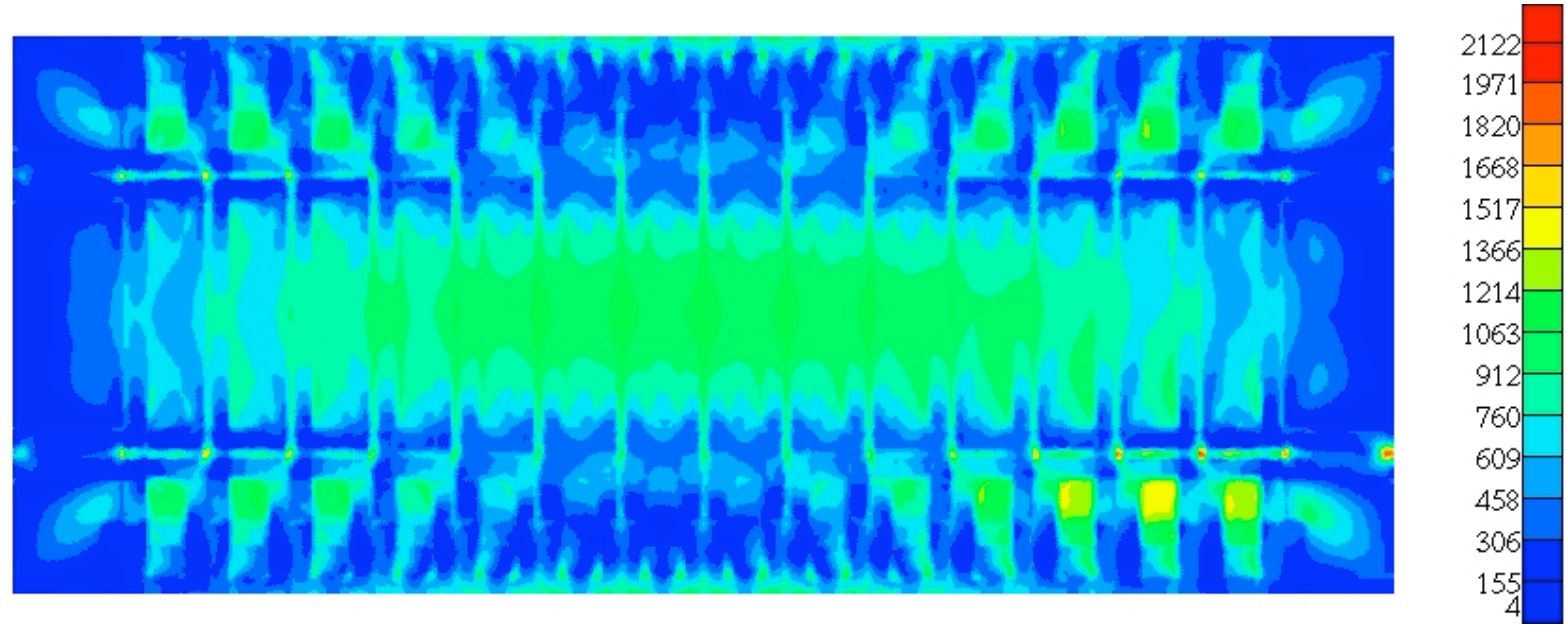

Fig. 11. Pressure panel maximum principal strains $(\mu \varepsilon)$ at $2 P$ from linear analysis. 

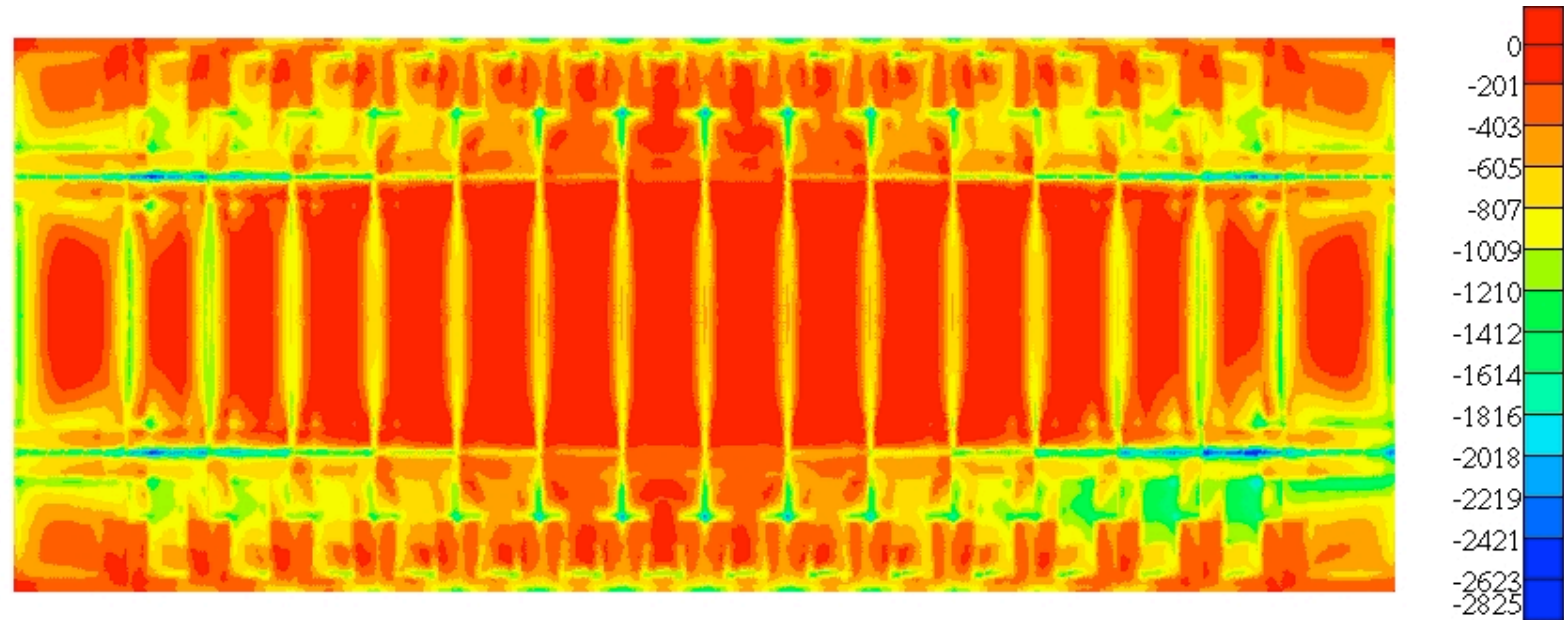

Fig. 12. Pressure panel minimum principal strains $(\mu \varepsilon)$ at $2 P$ from linear analysis.
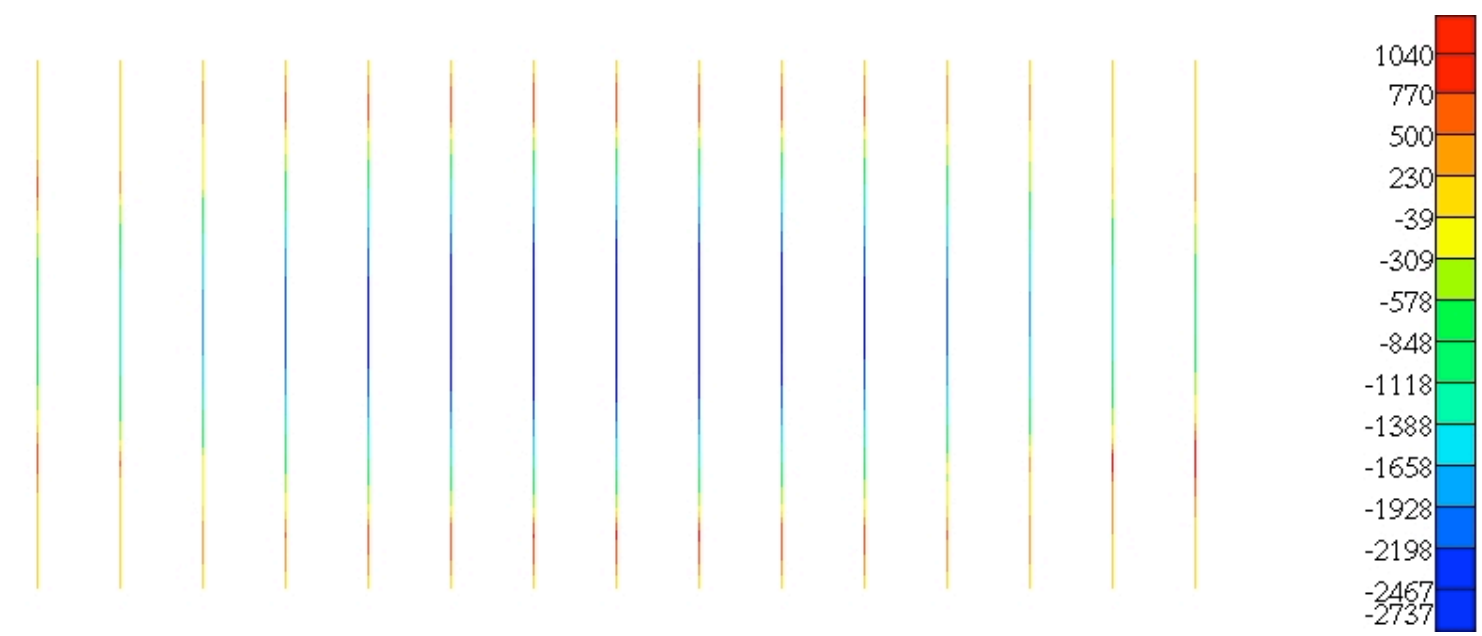

Fig. 13. Pressure panel stringer rod maximum strains $(\mu \varepsilon)$ at $2 P$ from linear analysis.
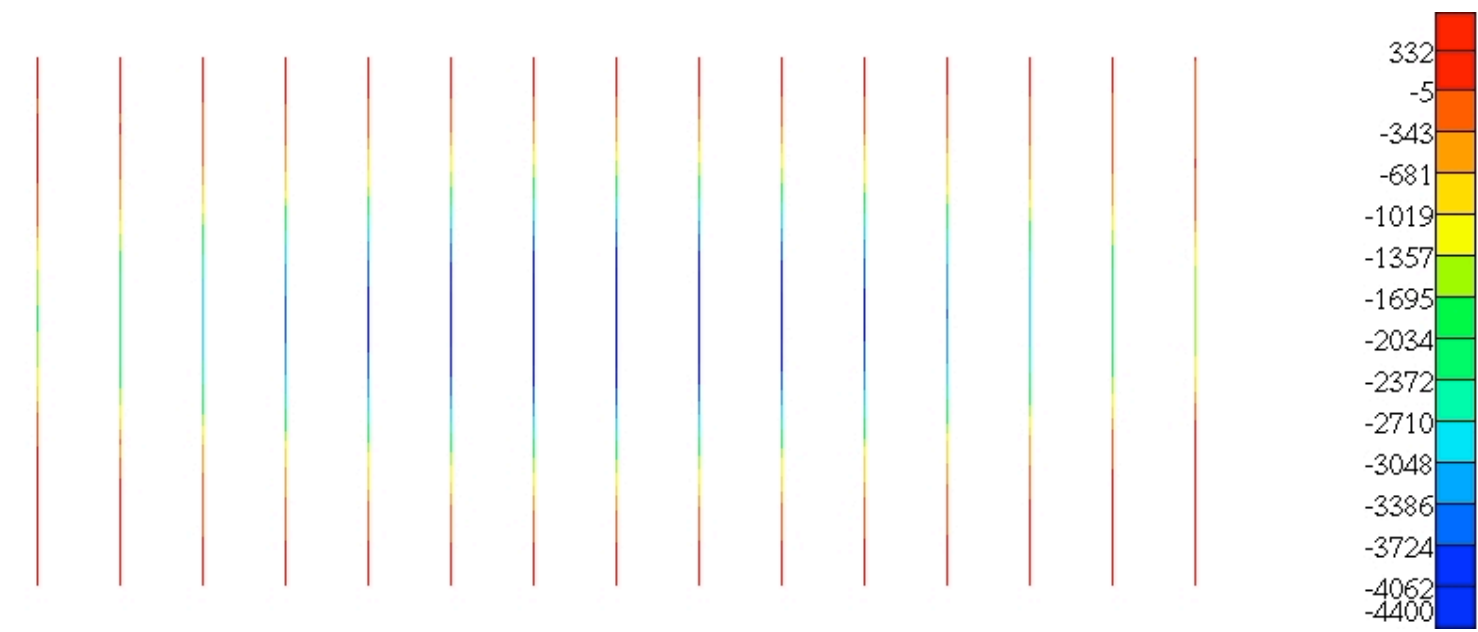

Fig. 14. Pressure panel stringer rod minimum strains $(\mu \varepsilon)$ at $2 P$ from linear analysis. 


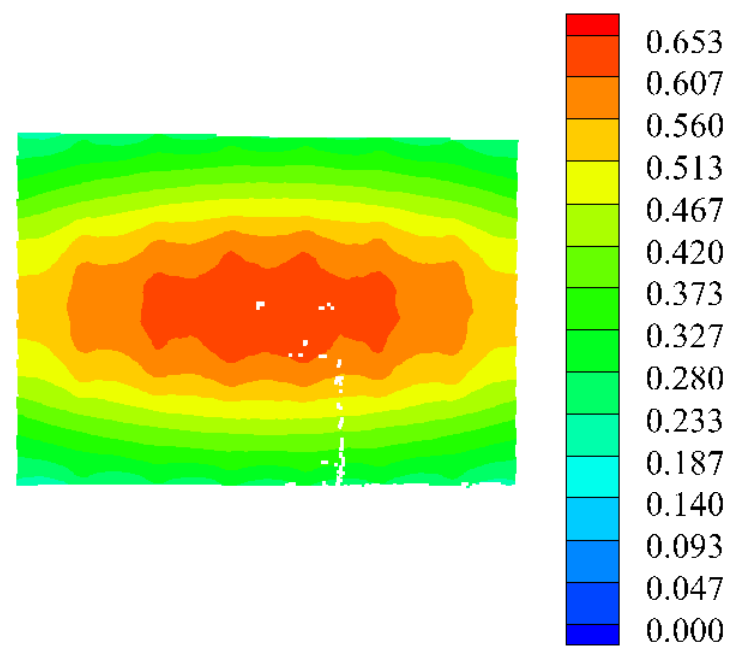

a) Experimental VIC
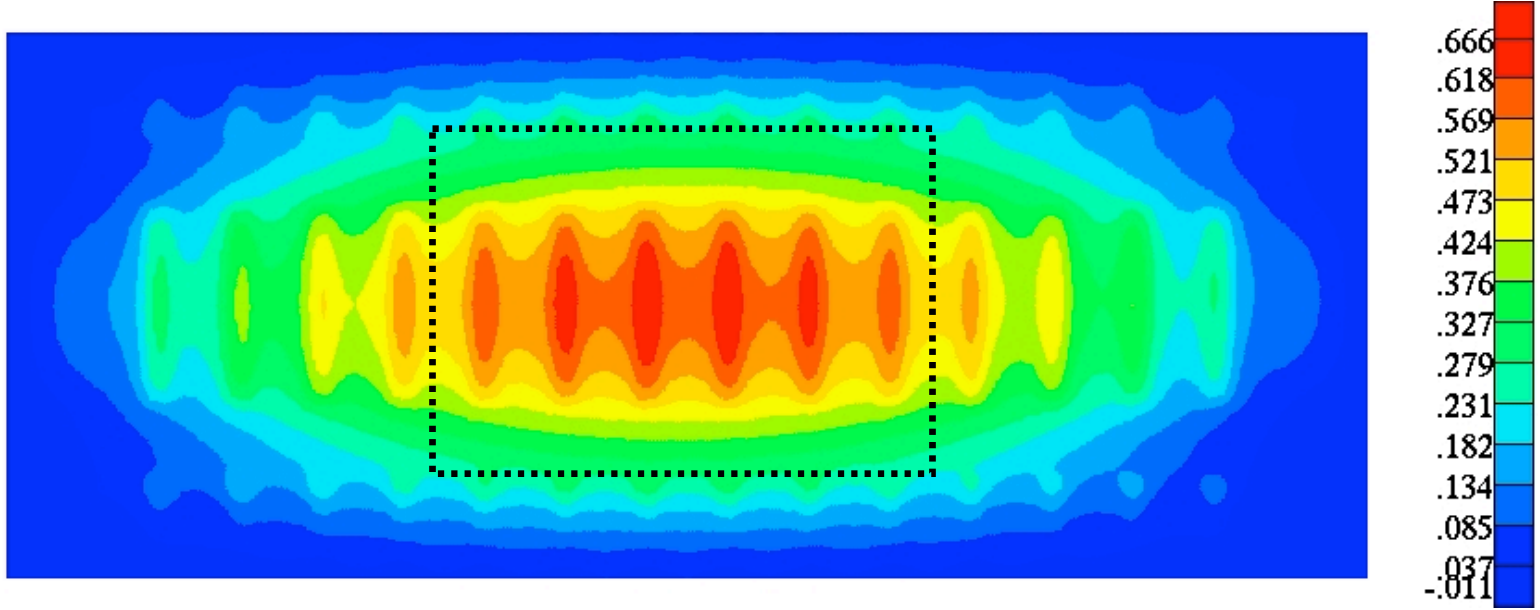

b) Linear analysis
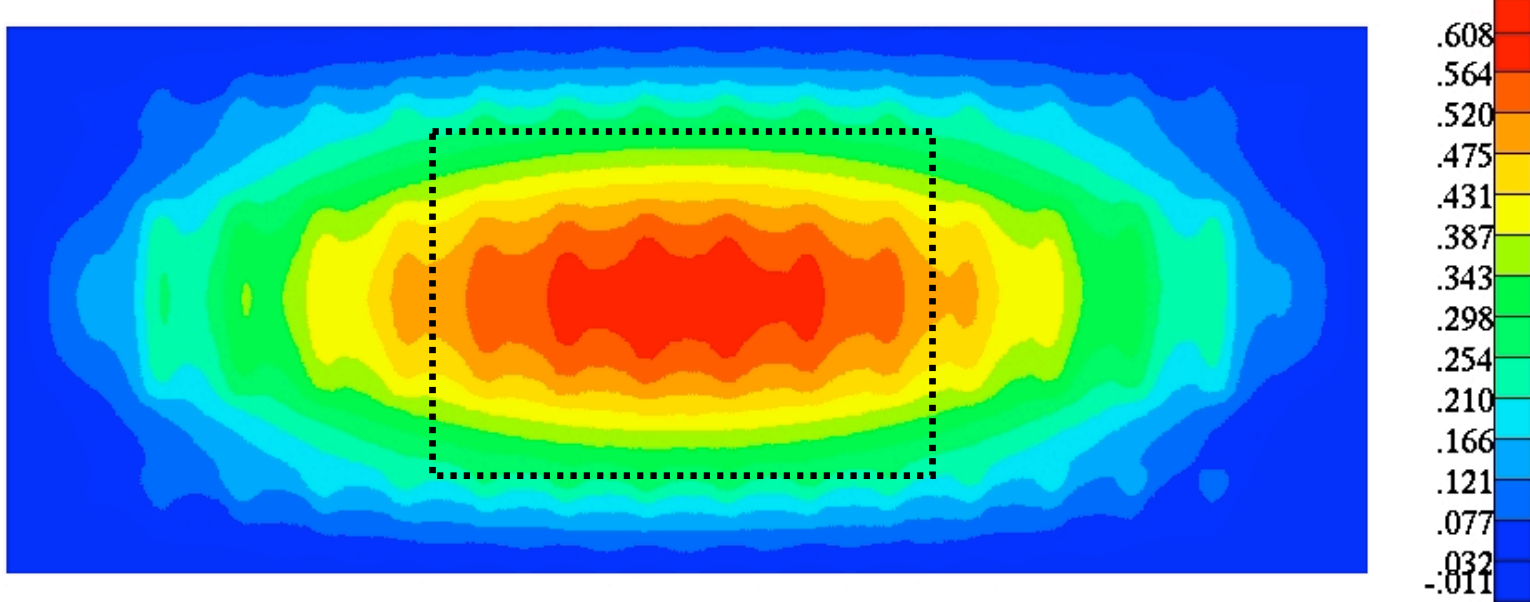

c) Nonlinear analysis

Fig. 15. Comparison of panel out-of-plane displacement contours at $2 P$. The outlined regions in $b)$ and c) correspond to the portion of analysis plots covered by the VIC data. 


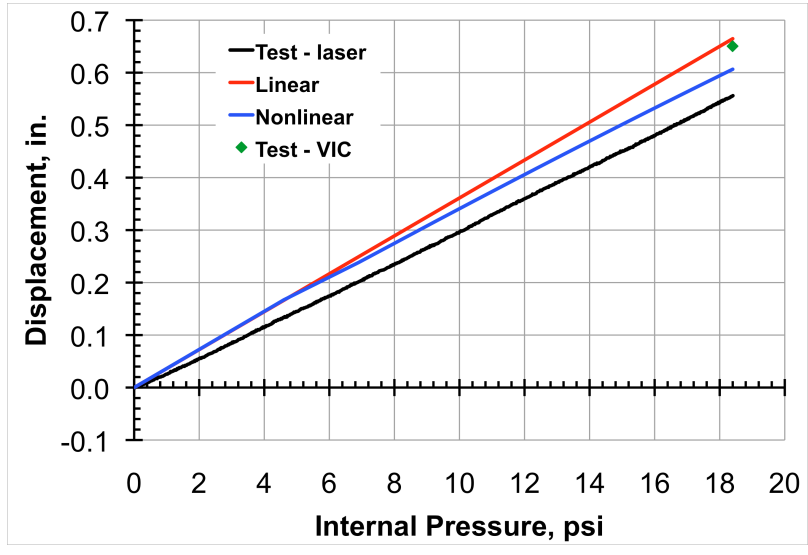

Fig. 16. Load/displacement comparison at laser displacement sensor location.

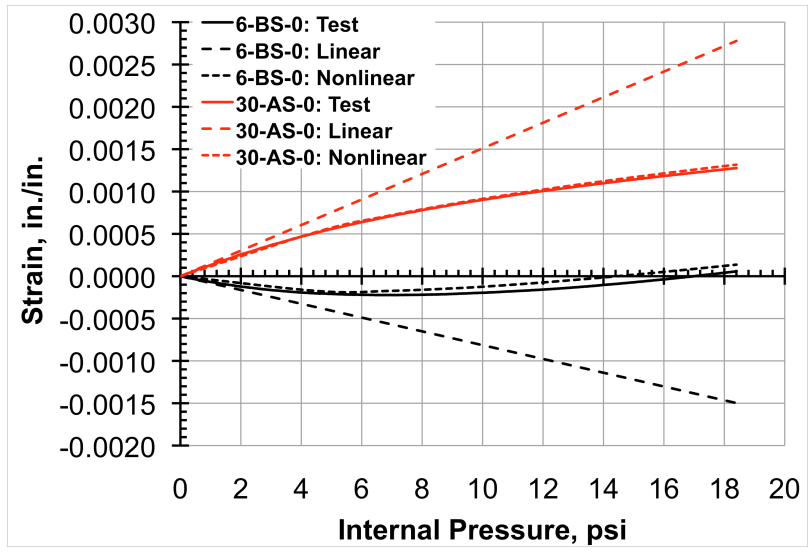

Fig. 18. Skin 0-degree strain gage comparison between test and analysis at panel center.

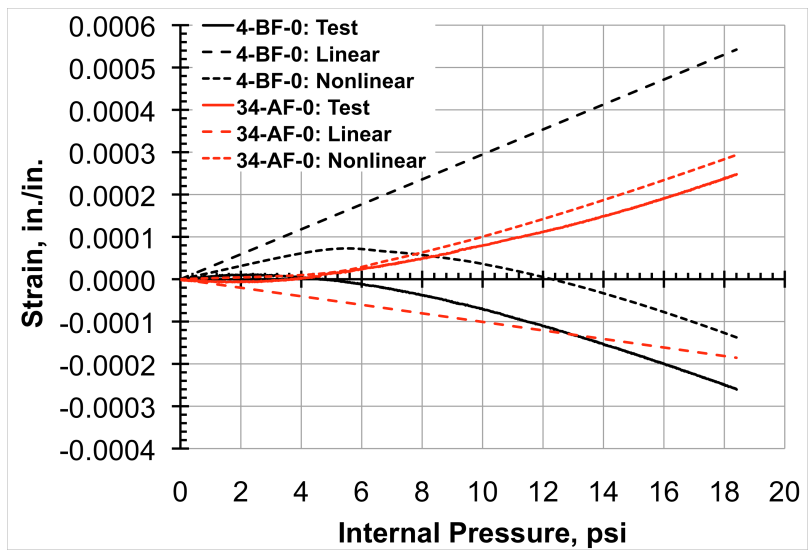

Fig. 20. Stringer flange 0-degree strain gage comparison between test and analysis at panel center.

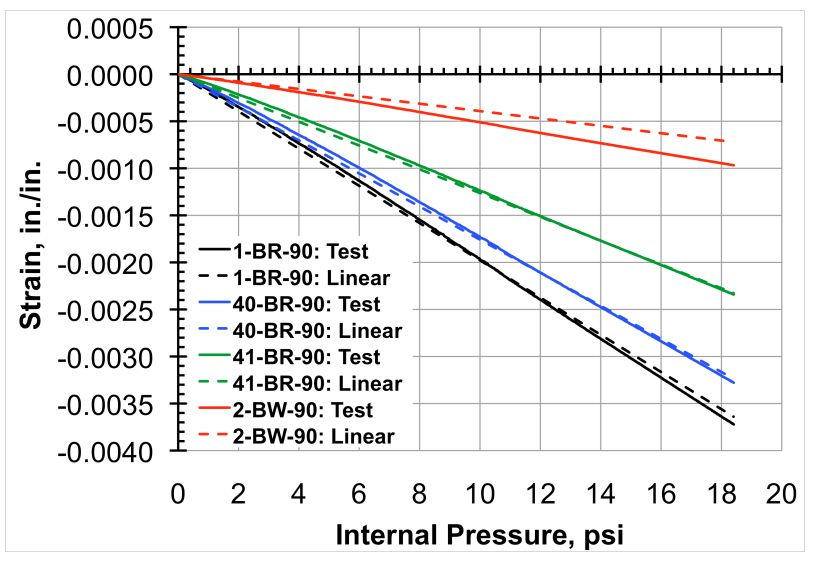

Fig. 17. Center stringer 90-degree strain gage comparison between test and linear analysis.

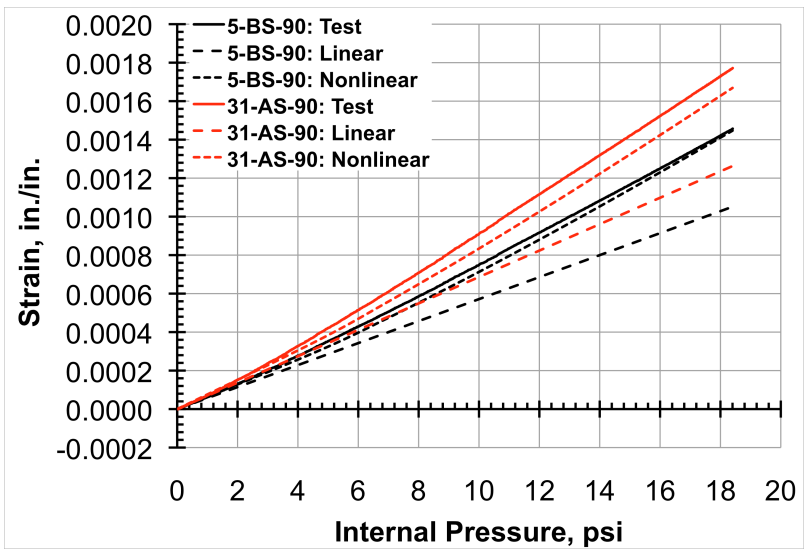

Fig. 19. Skin 90-degree strain gage comparison between test and analysis at panel center.

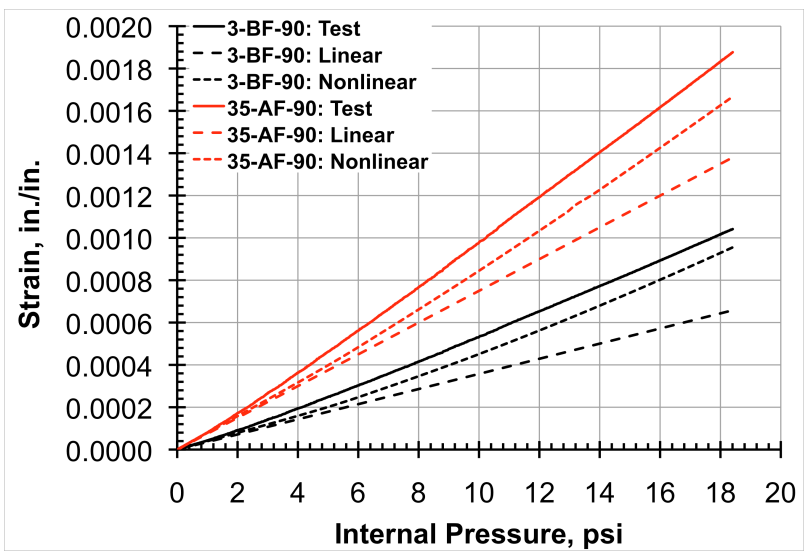

Fig. 21. Stringer flange 90-degree strain gage comparison between test and analysis at panel center. 


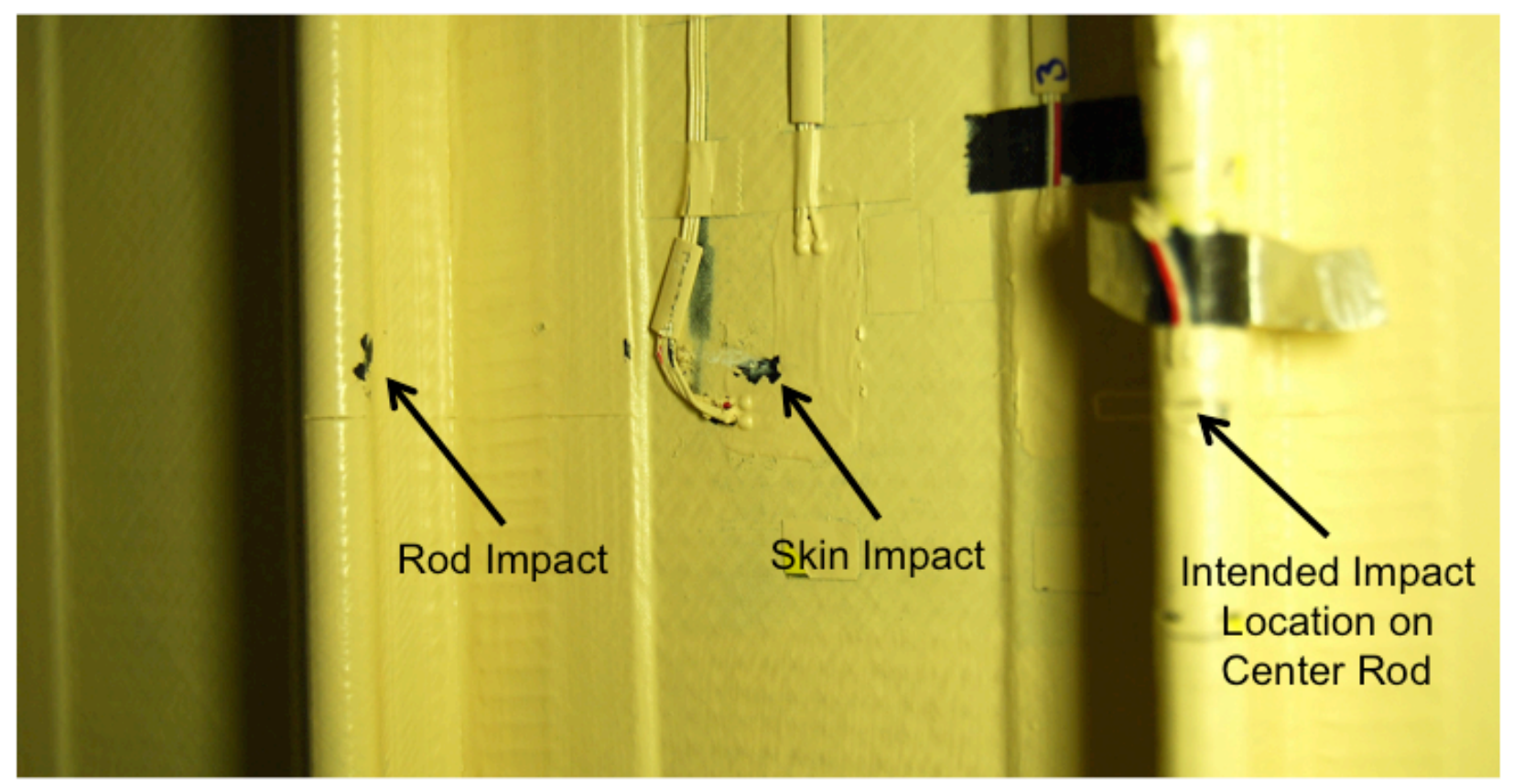

Fig. 22. Impact of panel skin and stringer.

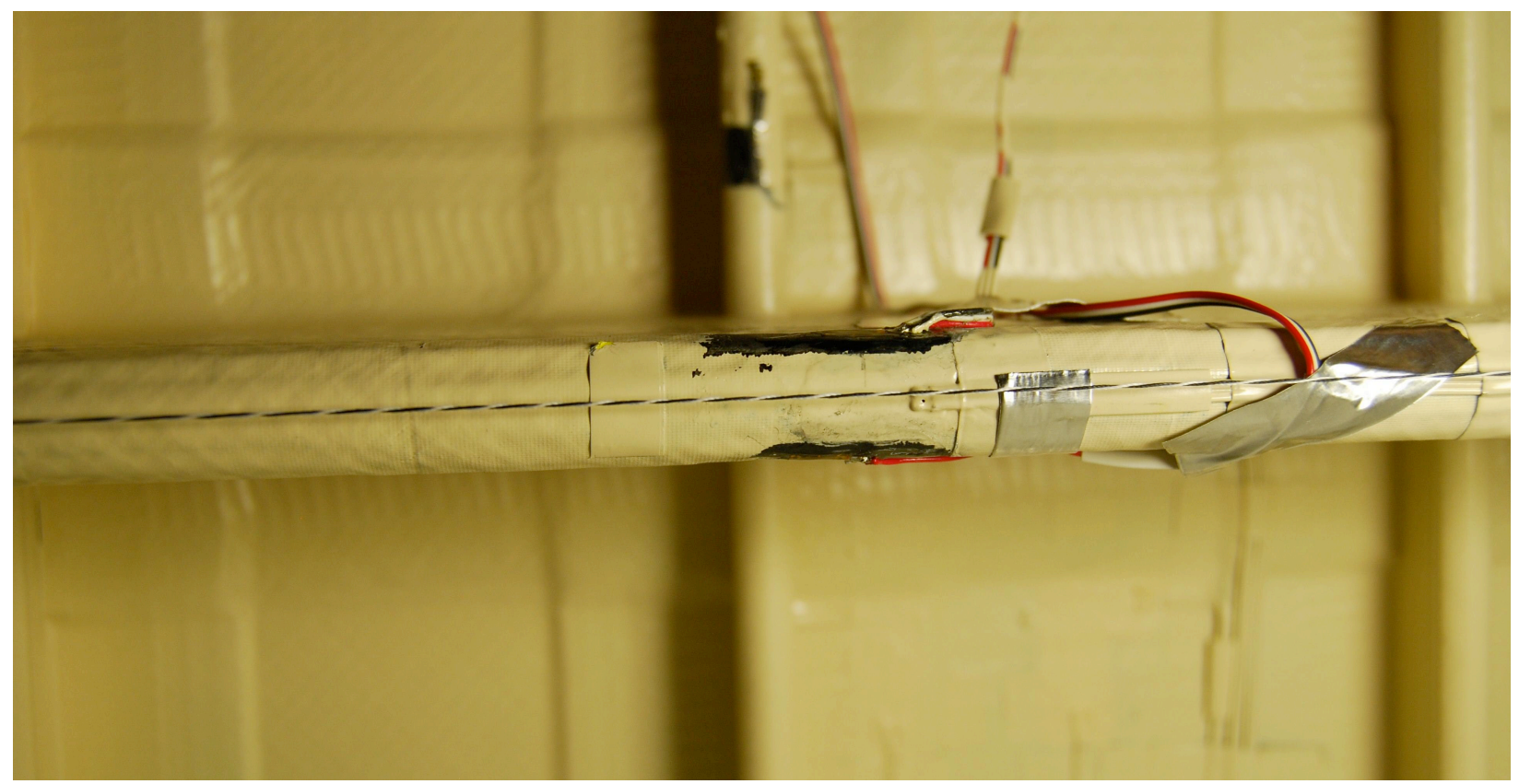

Fig. 23. Straightness of frame using twisted white and black thread. 


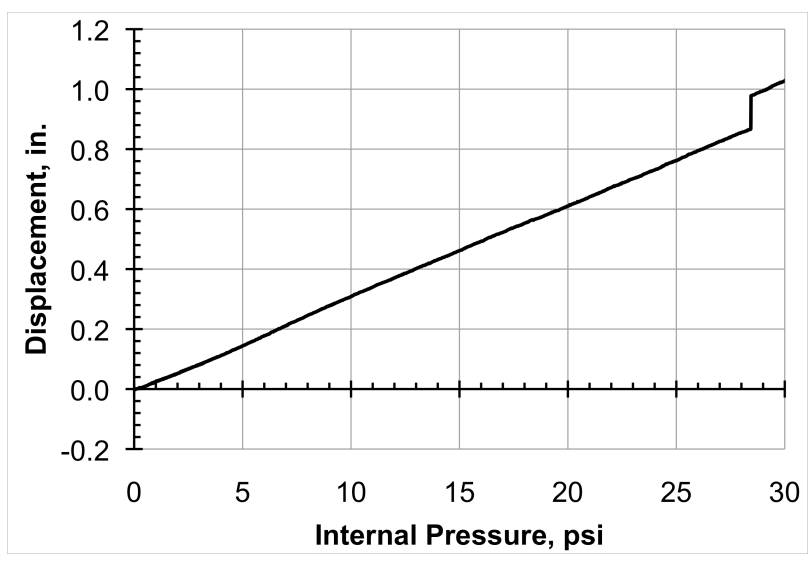

Fig. 24. Load/displacement response for load level 3 at laser displacement sensor location.

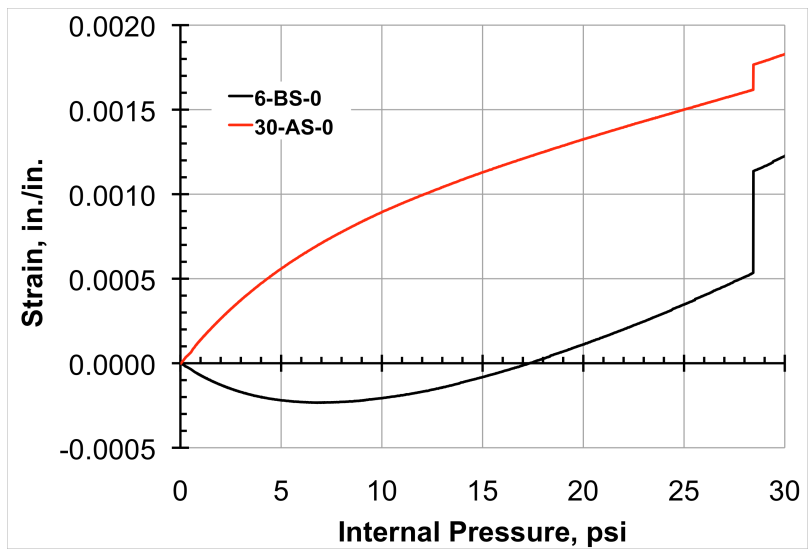

Fig. 26. Skin 0-degree strain gage response at panel center for load level 3 .

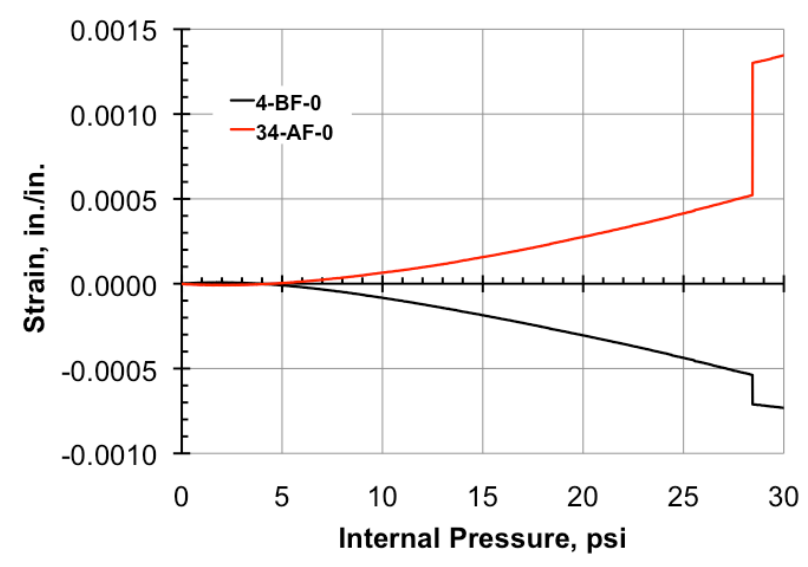

Fig. 28. Stringer flange 0-degree strain gage response at panel center for load level 3 .

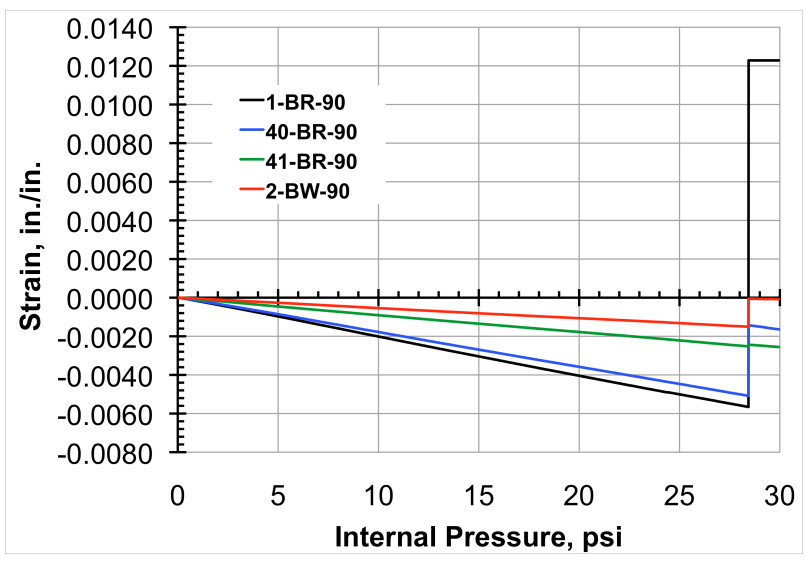

Fig. 25. Center stringer 90-degree strain gage response for load level 3.

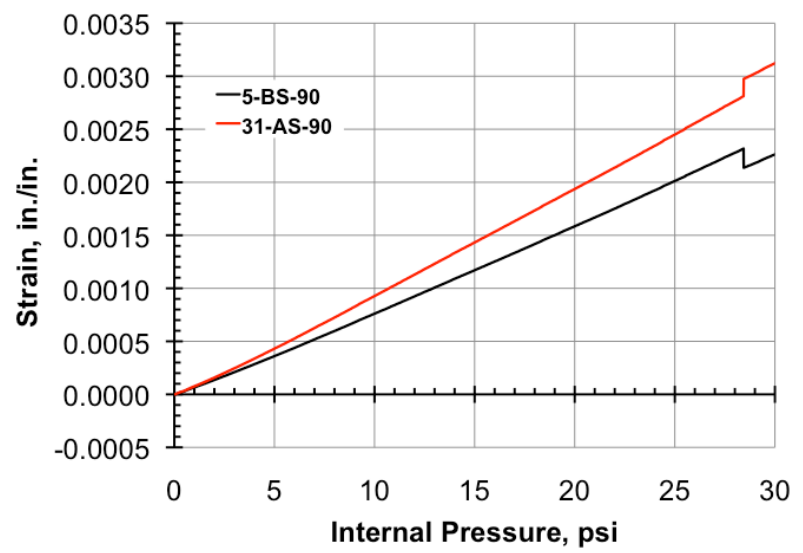

Fig. 27. Skin 90-degree strain gage response at panel center for load level 3 .

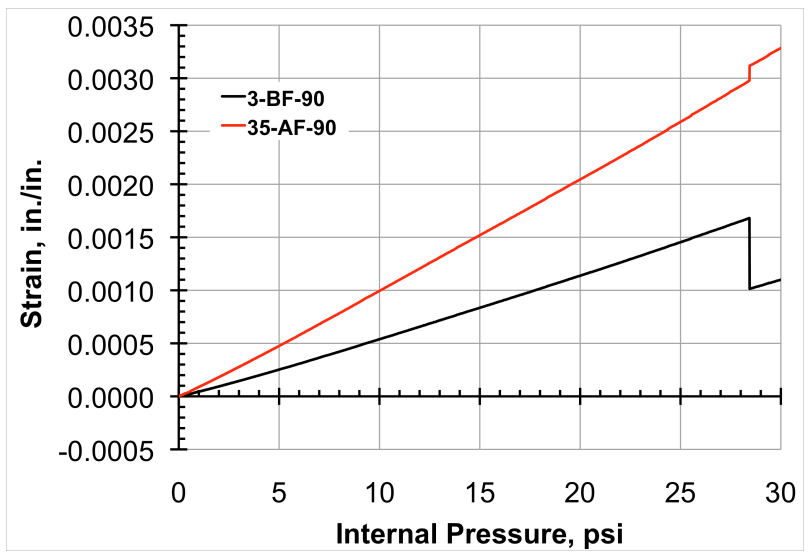

Fig. 29. Stringer flange 90-degree strain gage response at panel center for load level 3. 


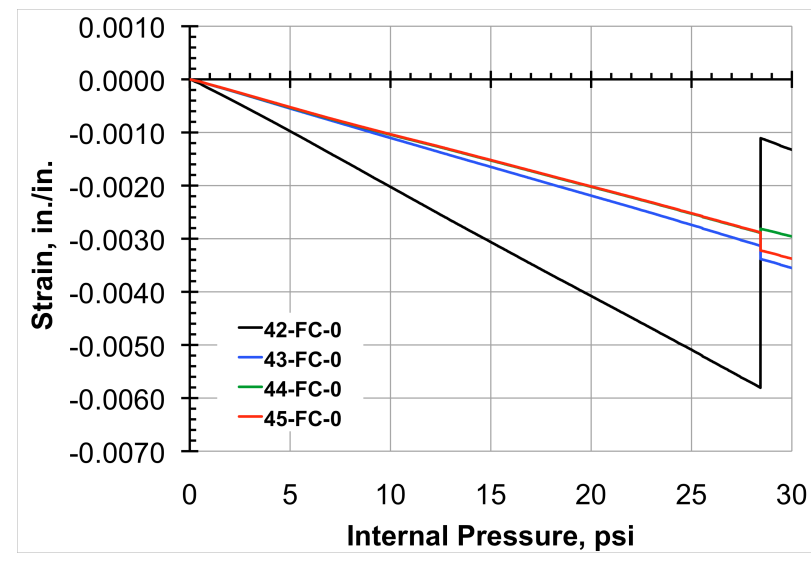

Fig. 30. Frame 0-degree strain gage response at frame center tops for load level 3.

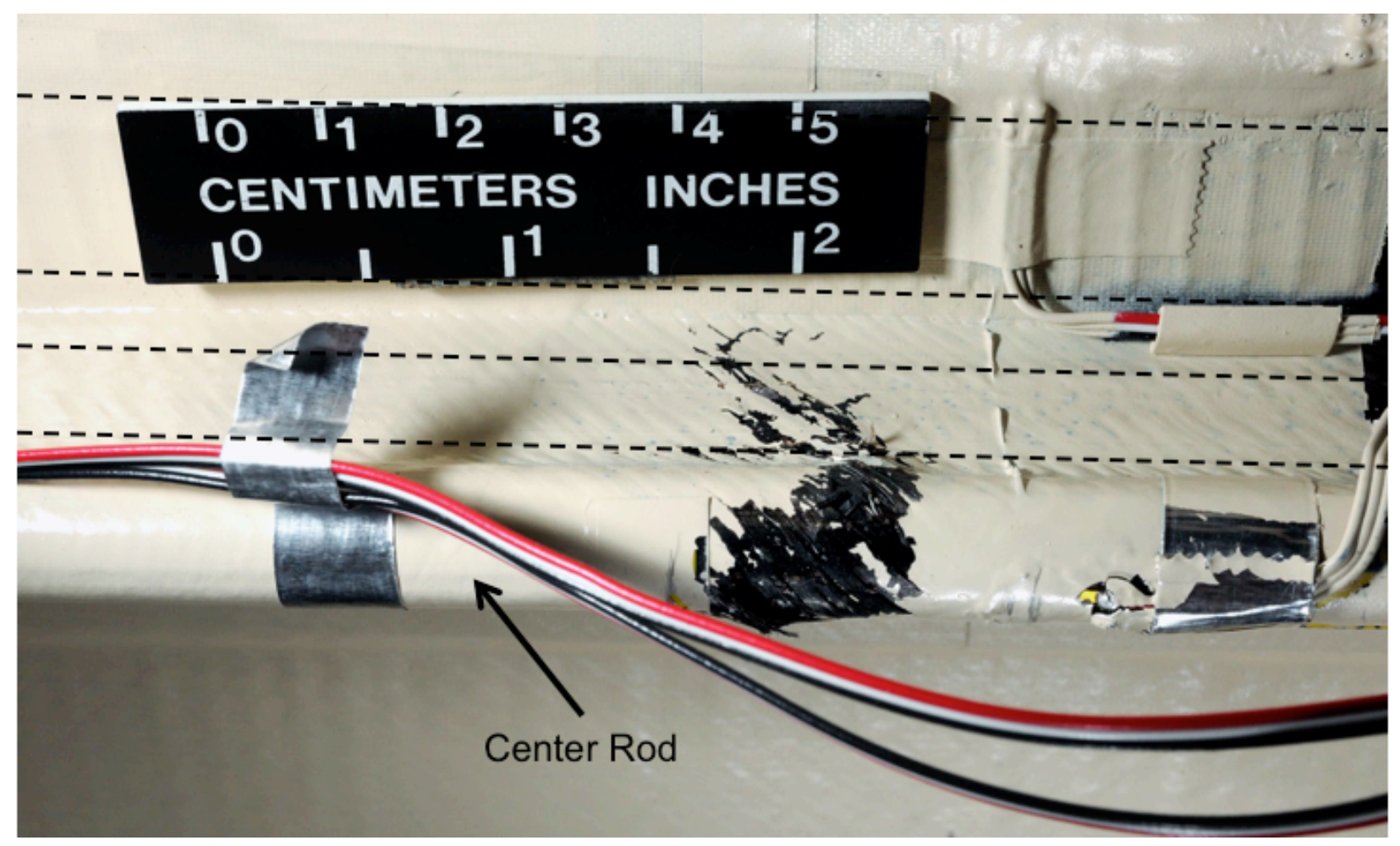

Fig. 31. Center rod damage, side 1. Stitch locations indicated by dashed lines. 


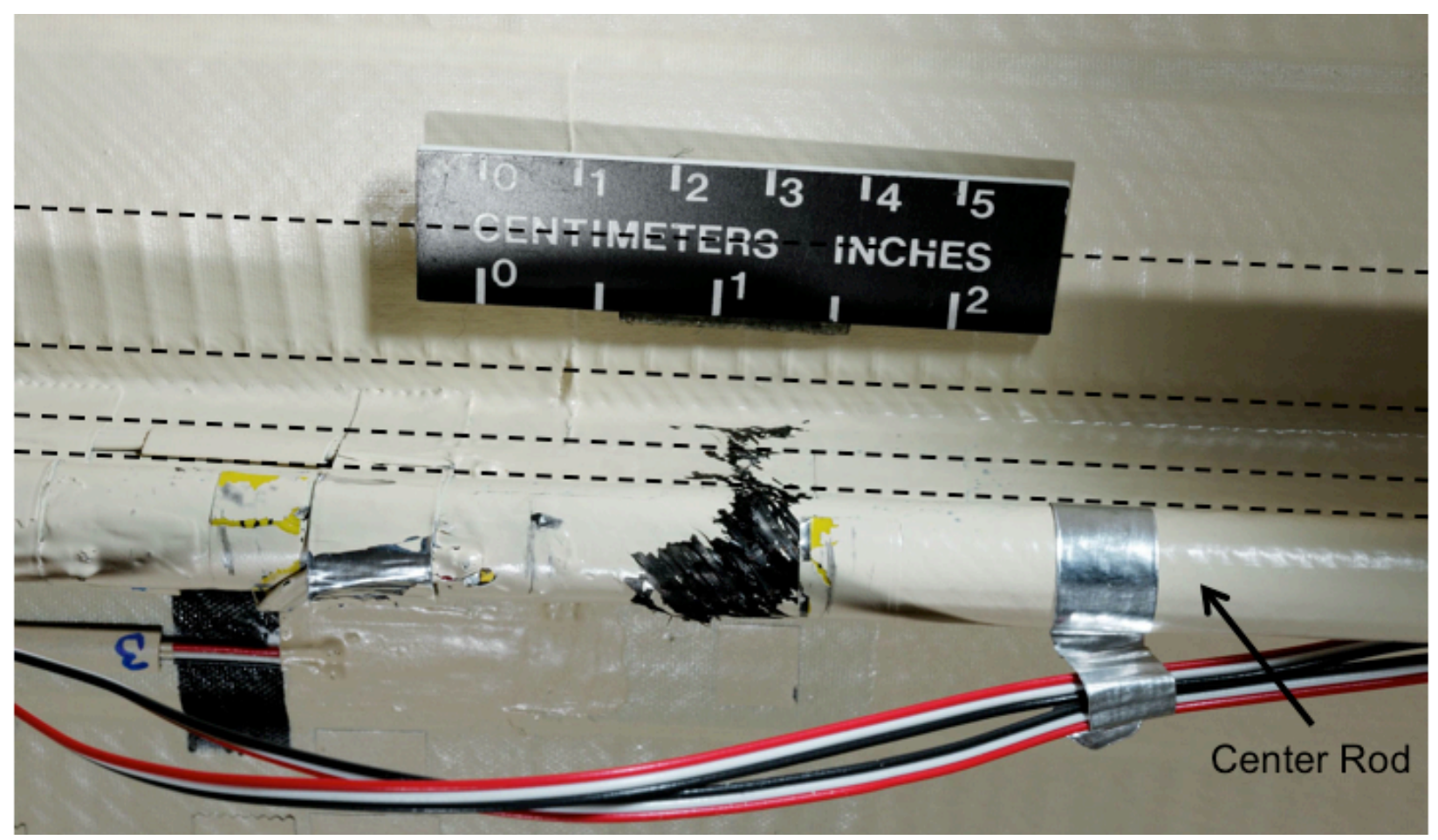

Fig. 32. Center rod damage, side 2. Stitch locations indicated by dashed lines. 